\title{
The Hedgehog protein family
}

\section{Thomas R Bürglin}

Address: Department of Biosciences and Nutrition, Karolinska Institutet, and School of Life Sciences, Södertörn University, Hälsovägen 7 , SE-141 57 Huddinge, Sweden. Email: thomas.burglin@ki.se

Published: 19 November 2008

Genome Biology 2008, 9:24I (doi:I0.I I86/gb-2008-9-II-24I)

The electronic version of this article is the complete one and can be

found online at http://genomebiology.com/2008/9/I I/24I

(C) 2008 BioMed Central Ltd

\begin{abstract}
Summary
The Hedgehog $(\mathrm{Hh})$ pathway is one of the fundamental signal transduction pathways in animal development and is also involved in stem-cell maintenance and carcinogenesis. The hedgehog ( $h h$ ) gene was first discovered in Drosophila, and members of the family have since been found in most metazoa. Hh proteins are composed of two domains, an amino-terminal domain HhN, which has the biological signal activity, and a carboxy-terminal autocatalytic domain $\mathrm{HhC}$, which cleaves $\mathrm{Hh}$ into two parts in an intramolecular reaction and adds a cholesterol moiety to $\mathrm{HhN}$. $\mathrm{HhC}$ has sequence similarity to the self-splicing inteins, and the shared region is termed Hint. New classes of proteins containing the Hint domain have been discovered recently in bacteria and eukaryotes, and the Hog class, of which Hh proteins comprise one family, is widespread throughout eukaryotes. The non-Hh Hog proteins have carboxy-terminal domains (the Hog domain) highly similar to $\mathrm{HhC}$, although they lack the $\mathrm{HhN}$ domain, and instead have other amino-terminal domains. Hog proteins are found in many protists, but the Hh family emerged only in early metazoan evolution. $\mathrm{HhN}$ is modified by cholesterol at its carboxyl terminus and by palmitate at its amino terminus in both flies and mammals. The modified $\mathrm{HhN}$ is released from the cell and travels through the extracellular space. On binding its receptor Patched, it relieves the inhibition that Patched exerts on Smoothened, a G-protein-coupled receptor. The resulting signaling cascade converges on the transcription factor Cubitus interruptus ( $\mathrm{Ci}$ ), or its mammalian counterparts, the Gli proteins, which activate or repress target genes.
\end{abstract}

\section{Gene organization and evolutionary history}

Hedgehog (Hh) proteins are composed of two distinct domains, the amino-terminal 'Hedge' domain $(\mathrm{HhN})$, and the carboxy-terminal 'Hog' domain (HhC) (Figure 1 and Box 1). The founding member of the $h h$ gene family was first discovered in genetic screens in Drosophila melanogaster [1] and, once the gene was cloned [2-4], vertebrate members were soon found [5-7]. Drosophila has a single $h h$ gene, mammals have three paralogous genes, called Sonic Hedgehog (Shh), Indian Hedgehog (Ihh), and Desert Hedgehog (Dhh), and the cnidarian Nematostella vectensis has two paralogous $h h$ genes, Nv_HH1 and Nv_HH2 [8]. The $h h$ gene family is present throughout the Eumetazoa, although it has been lost in some nematodes. For example, Caenorhabditis elegans has no $h$ h gene but has other genes related to $h h$ via the Hog domain. These $h h$-related genes have been grouped into different families, such as Warthog (wrt), Groundhog ( $g r d$ ), and Quahog (qua), and are characterized by having amino-terminal sequences distinct from HhN $[9,10]$.

Soon after the discovery of the fly and vertebrate $\mathrm{Hh}$ proteins, it was noticed that their carboxy-terminal autoproteolytic domains were similar in sequence to the selfsplicing inteins [11]. Inteins are protein sequences that autocatalytically splice themselves out of longer protein precursors - analogous to introns - and ligate the flanking regions into a functional protein $[12,13]$. The determination of the X-ray structure of the Drosophila HhC domain confirmed this similarity, and the region of similarity was named the Hint module [14] (see Figure 1). More recently, new classes of Hint-containing proteins with various types of processing activity have been recognized in bacteria and eukaryotes $[10,13,15,16]$ (Figure 2). Intein-containing genes 


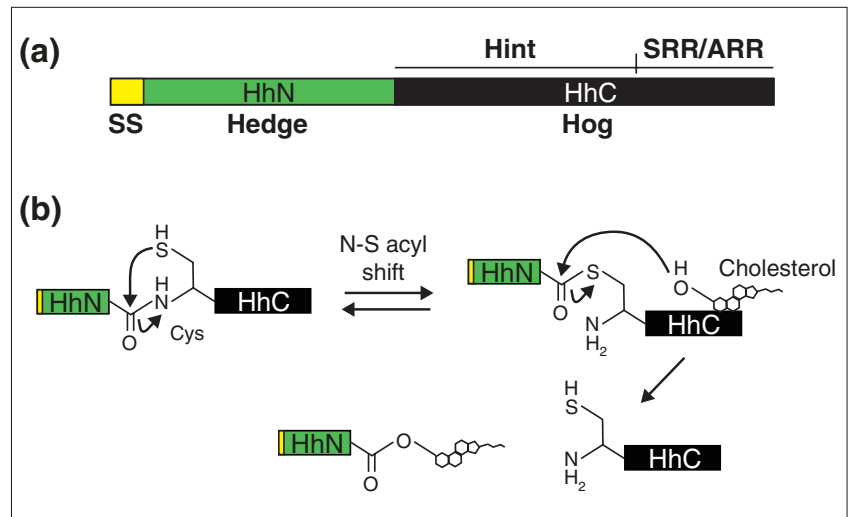

Figure I

Structural features of $\mathrm{Hh}$ proteins. (a) Signal peptide sequence for protein export (SS, yellow), the amino-terminal signaling domain ( $\mathrm{HhN}$, green), and the autocatalytic carboxy-terminal domain ( $\mathrm{HhC}$, black) are indicated. Both $\mathrm{HhN}$ and $\mathrm{HhC}$ domains are also found in proteins other than the $\mathrm{Hh}$ family, and are therefore globally referred to as 'Hedge' and 'Hog', respectively. The Hog domain itself can be separated into two regions; the first twothirds shares similarity with self-splicing inteins, and this module has been named Hint, whereas the carboxy-terminal third binds cholesterol in $\mathrm{Hh}$ proteins and has been named the sterol-recognition region (SRR) [14]. In $\mathrm{Hog}$ proteins other than $\mathrm{Hh}$, that is, Hh-related proteins, this region is referred to as ARR (adduct recognition region) [2I], as the nature of the adduct is not known. (b) Intramolecular autoprocessing of Hh. Acids and bases assisting in catalysis are not shown (figure adapted from [14,70]).

are present in all three kingdoms of life, but Hog genes and Vint genes - a novel class of proteins sharing a VWA domain

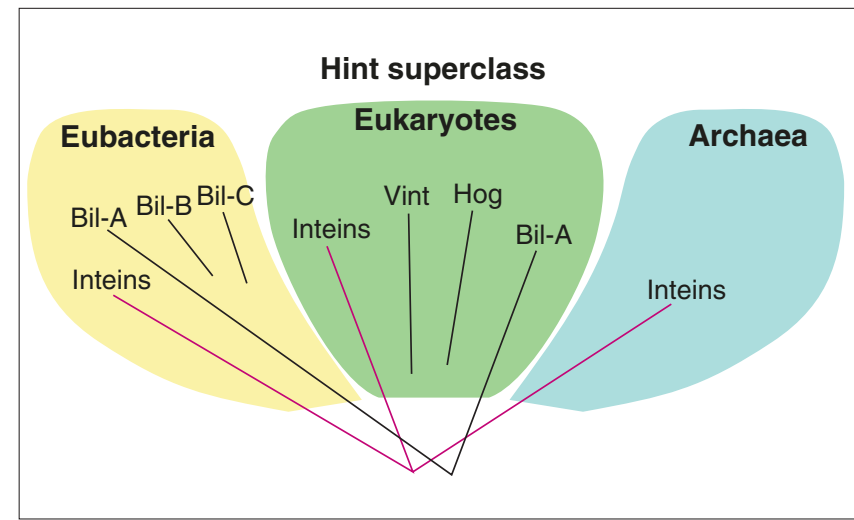

Figure 2

Distribution of Hint superclass genes in the three domains of life. Hint genes can be divided into several different classes: inteins; Bil-A (bacterial intein-like genes type $\mathrm{A}$ ); Bil-B; a new class referred to here as Bil-C $[10,13]$; Vint (VWA domain and Hint domain proteins) [10]; and Hog.

(von Willebrand factor type A domain) and a Hint domain are known only from eukaryotes at present (Figure 2). Initially, Hog genes, primarily members of the Hh family, were found only in metazoa, but they have recently been found in many different branches of protists $[10,13,17,18]$ (Figure 3). This widespread distribution indicates that the Hog domain must be of ancient origin and have emerged early in eukaryote evolution. Hog genes are absent in higher plants and several fungal clades, which is presumably due to

\section{Box 1. Terminology}

Hint domain/module: an autoproteolytic domain/module originally described in Hedgehog proteins and selfsplicing inteins. The Hint-containing group of proteins encompasses several distinct classes, such as inteins, the Hog proteins (including the $\mathrm{Hh}$ family), as well as as Bil-A, Bil-B, and Vint.

Hog proteins: class of Hint proteins with a distinct subtype of Hint domain and a carboxy-terminal ARR found in many eukaryotic phyla. The Hint and ARR regions together comprise the Hog domain.

Hedgehog (Hh): one family of Hog proteins found in eumetazoa, composed of an amino-terminal Hedge (HhN) domain and a carboxy-terminal Hog (HhC) domain.

Hedge domain: comprehensive term for the amino-terminal domain of Hh proteins and of Hedgling proteins (which lack a Hog domain).

HhN and HhC: amino-terminal and carboxy-terminal domains specifically of Hh family proteins.

Hh-related genes: a comprehensive term used for those Hog proteins that have amino-terminal domains different from that of $\mathrm{Hh}$, for example, the Quahog, Warthog, and Groundhog families in nematodes.

SRR: sterol-recognition region, the cholesterol-binding site of $\mathrm{HhC}$.

ARR: adduct recognition region in the Hog domain of Hh-related proteins 


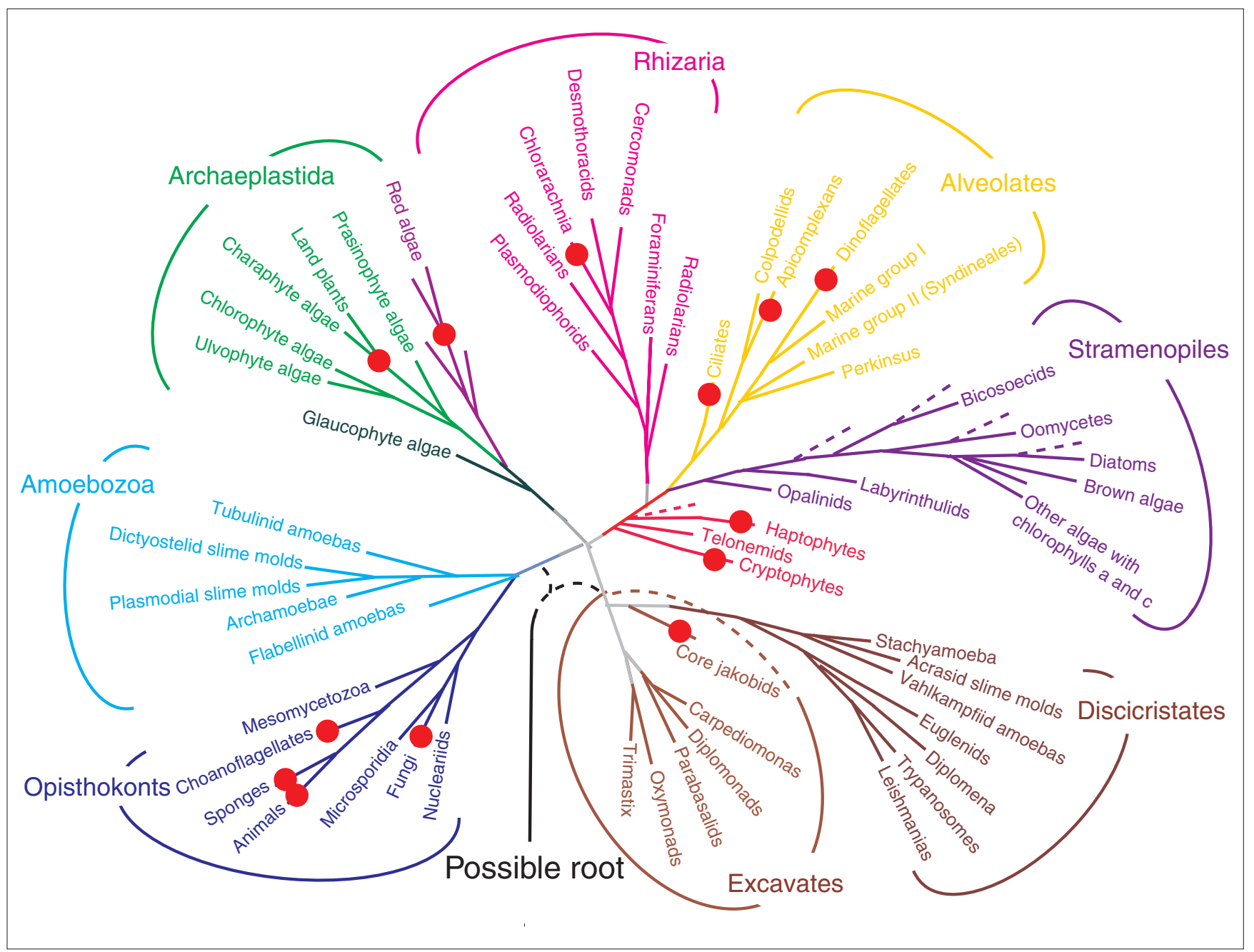

Figure 3

Consensus phylogenetic tree of eukaryotes. The branches where Hog domain containing proteins are found are indicated with red dots. With permission from Sandra Baldauf, (see, also [7I]).

gene loss. Many of the protist Hog proteins, as well as the metazoan non-Hh Hog proteins - referred to as Hh-related proteins - have putative secreted domains upstream of the Hog domain [10]. In most cases these upstream regions show conservation only with related Hog genes within the same phylum, suggesting a gradual evolution of the amino-terminal regions within each phylum. In a few instances, such as the fungus Glomus mosseae [17], the choanoflagellate Monosiga ovata [18], and the sponge Amphimedon queenslandica [19], the Hog domain is fused to other well-conserved domains, indicative of a merging of two distinct domains.

The Hedge domain seems to be of more recent origin. It has been found in sponges and Cnidaria in a large extracellular membrane protein called Hedgling [19]. In addition to the Hedge domain at the amino terminus, Hedgling contains many additional domains, such as a VWA domain and numerous cadherin repeats, but lacks a Hog domain [10,19]. A second, divergent fragment of a Hedge domain has been found in the sponge Oscarella carmela that also seems to lack a Hog domain [10,20]. At present, no $h h$ genes have been found in sponges, but they are present in Cnidaria. Two scenarios can be envisaged for the emergence of $\mathrm{Hh}$ proteins proper (Figure 4). One is that the Hedge domain evolved from a secreted amino-terminal domain already associated with the Hog domain. Hedgling is then derived from $\mathrm{Hh}$ by a 'split' of Hedge from Hog before the emergence of sponges. The other is that the Hedge domain evolved in an extracellular protein such as Hedgling. During the emergence of Eumetazoa, the Hedge domain 'fused' with a Hog protein to give rise to Hh. Examples of both domain split and loss and domain-merging events are documented for Hog proteins, and therefore do not help to discriminate between alternative scenarios. 


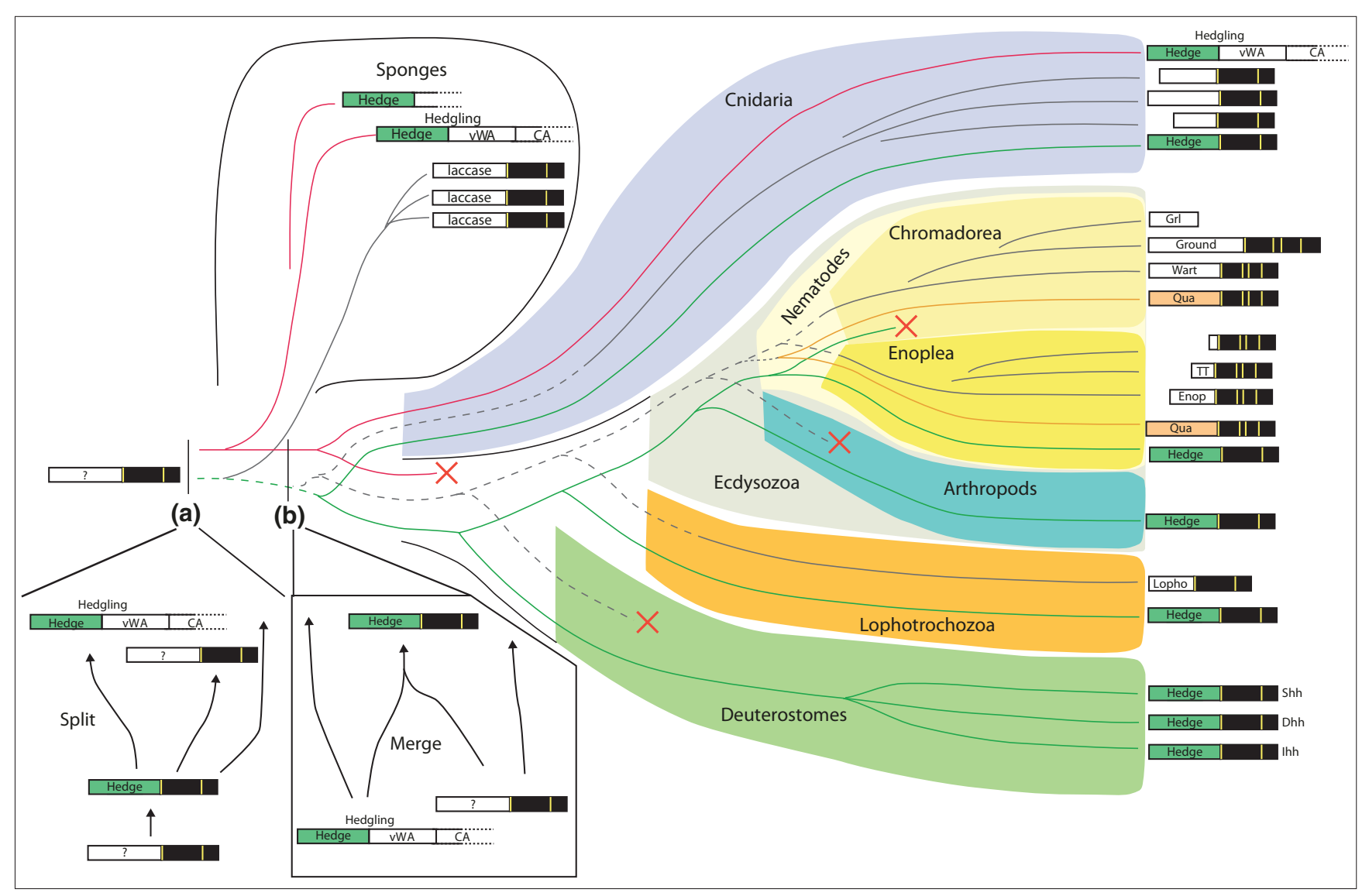

\section{Figure 4}

One possible scenario for the evolution of $h h$ and $h h$-related genes in metazoa. Different phylogenetic branches are outlined, and gene families known at present are shown. Dotted lines indicate uncertain evolutionary connections. Hedgling genes are currently known only from sponges and Cnidaria $[8,10,19]$. The Hh family could have originated in two possible ways. (a) The Hedge domain evolved concomitantly with the Hog domain from a protist Hog protein before the emergence of the Metazoa. A duplication of the Hedge domain and merger with an extracellular protein gave rise to the Hedgling gene. (b) No $h$ h gene existed at the emergence of sponges. The Hedge domain of a Hedgling gene duplicated and merged with a Hog gene to give rise to hh in early Eumetazoa. Cnidaria, Lophotrochozoa and nematodes contain both $\mathrm{Hh}$ as well as other Hog family genes. The phylogenetic analysis cannot unequivocally resolve whether these other families originated from a single ancestor in Eumetazoa - as shown here with dotted lines - or whether, at least in some phyla, duplication and divergence from a $h$ gene gave rise to new families in particular phyla.

Very recent findings have led to a revised understanding of the evolution of $h h$ genes and the $h h$-related genes in metazoa. In Drosophila and vertebrates only $h h$ genes are found, but both $h h$ and $h h$-related genes are present in the Cnidaria, nematodes and also the Lophotrochozoa $[8,10]$. I have searched the genome sequences of two lophotrochozoan species, the limpet Lottia gigantea and the polychaete worm Capitella I ECS-2004, and retrieved one $h h$ gene and six $h h$-related genes from L. gigantea and one $h h$ gene and one $h h$-related gene from Capitella. These sequences have been combined with previously published sequences to generate a new phylogenetic tree based on the Hog domain (Figure 5). The most interesting observation from the tree is that the $h h$-related genes Cap_213608 and Lg_236513 form a clade, and these two sequences also share sequence similarity just upstream of the Hog domain. Therefore, it seems likely that a new $h$ h-related gene family, which I refer to as 'Lophohog', exists in the Lophotrochozoa and developed in parallel with $\mathrm{Hh}$. On the basis of this observation, the following model could be proposed for the evolution of $h \mathrm{~h}$ and $h h$-related genes in metazoa (see Figure 4). I suggest that at least one $h h$ and one $h h$-related gene existed at the origin of the Eumetazoa, giving rise to the $h h$ and $h h$-related genes in the Cnidaria, the Lophotrochozoa, and nematodes. In Drosophila and deuterostomes the $h h$-related gene was lost, whereas in the nematode branch leading to C. elegans, $h h$ was lost. The most radical alternative scenario would be that the $h$ h-related genes in Cnidaria, Lophotrochozoa, and nematodes are all derived independently from a $h h$ gene in each phylum. Intermediate scenarios, where $h h$-related genes evolved from a $h$ h gene only in one or two phyla, could also be possible. Phylogenetic analysis does not give definitive answers yet, but may resolve the question in the future, when additional genomes are sequenced. 


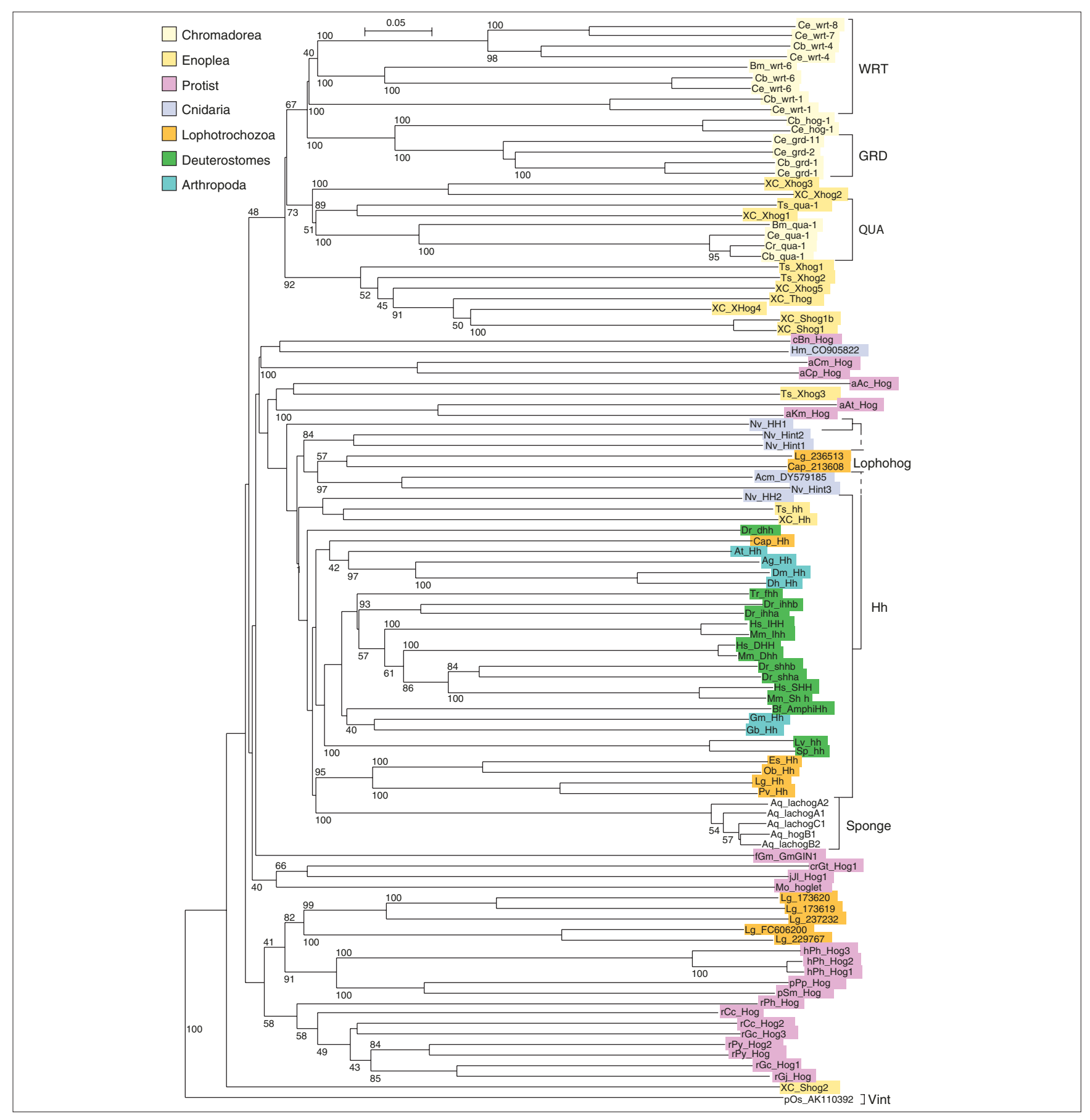

Figure 5

Neighbor-joining phylogenetic tree of eukaryote Hog domain protein sequences. The Hh, Groundhog (Grd), Warthog (Wrt), Quahog (Qua), and new Lophohog families are indicated. Sequence names are color-coded according to phyletic divisions, except for sponges. Chromadorea and Enoplea are two major nematode divisions. Protist is loosely used to encompass all non-metazoans. The Hint domains of Vint proteins were used as outgroup and bootstrap values $\geq 40 \%$ are shown. Most of the sequences and the analysis methods are described in [10]. Additional sequences were added to this analysis from sponges [19], and BLAST searches were carried out at JGI [72] of the genomes of L. gigantea and Capitella I ECS-2004. From Capitella I ECS-2004 one $h h$ and one $h h$-related gene were retrieved, and from $L$. gigantea one $h h$ and six other Hog genes were retrieved. Capitella Cap_213608 and $L$. gigantea $L$ g_ 236513 , which encodes an export signal peptide, form a clade, although not with high bootstrap significance. Interestingly, this clade clusters with the Cnidarian $h$-related genes - although bootstrap values are insignificant. Five $L$. gigantea Hog genes $\left(\operatorname{Lg} \_173620, \mathrm{Lg} \_173619, \mathrm{Lg} \_237232\right.$, Lg_FC606200, Lg_229767) form a distinct clade, but these genes are very divergent from the Hog domains of the other metazoan genes. These genes encode only a few residues upstream of the Hog domain (7-15), and lack an export signal peptide. This unusual structure is confirmed by multiple expressed sequence tags (ESTs) for each gene. Do these genes represent a highly divergent form of Hog-only proteins in this gastropod, or do they stem from another organism, perhaps some ciliated protozoan parasite found in L. gigantea [73]? More analysis will be necessary to resolve this. 


\section{Characteristic structural features}

Hh proteins are synthesized as precursor proteins (about 400-460 amino acids long) and comprise several different motifs and domains: a signal peptide for protein export, a secreted amino-terminal HhN (Hedge) domain that acts as a signaling molecule, and an autocatalytic carboxy-terminal $\mathrm{HhC}$ (Hog) domain that contains a Hint module (see Figure 1). Multiple sequence alignments of the $\mathrm{HhN}$ and $\mathrm{HhC}$ domains defining the conserved residues and features have been presented in [10]. HhC binds cholesterol in the sterolrecognition region (SRR) [21]. The catalytic activity of the Hint module cleaves Hh into two parts and adds the cholesterol moiety to the carboxyl terminus of HhN (Figure 1b). The structure of Drosophila $\mathrm{HhC}$ has been determined using $\mathrm{X}$-ray crystallography and shows a high congruence with that of inteins [14]. The structure is globular, composed of $\beta$ strands, and starts with a cysteine residue critical for autoprocessing (Figure $1 \mathrm{~b}$ ). The nematode Hh-related protein WRT-1 was shown to be autoprocessed like $\mathrm{Hh}$ [22]. Given that the critical residues of the active site of $\mathrm{HhC}$ are well conserved among Hog proteins [10,14], it can be assumed that most, if not all, are autoprocessed. However, it is not known what adduct binds to the adduct-recognition region (ARR) of Hh-related proteins. Intriguingly, the ARR regions of some of the protist Hog proteins contain motifs conserved with the Hh SRR [10], suggesting that sterol binding might be an ancient feature.

The structure of the $\mathrm{HhN}$ domain of mouse Shh has also been determined [23]. It is a relatively globular domain with two antiparallel $\alpha$ helices and several $\beta$ strands wrapping one face of the two helixes. Although it was found to have a potential catalytic site, no enzymatic activity has been uncovered so far [24]. In addition to the cholesterol modification, the $\mathrm{HhN}$ domain is also modified at its amino terminus by palmitate through the action of a transmembrane acyltransferase, named Skinny hedgehog (Ski, also known as Rasp) in Drosophila [25], and hedgehog acyltransferase (HHAT) in mammals [26]. Because of these lipid modifications, the modified $\mathrm{HhN}$ domain $(\mathrm{M}-\mathrm{HhN})$ can form multimeric complexes $[27,28]$ and can interact with lipoproteins [29]. Drosophila Ihog (interference hedgehog) and its mammalian orthologs Cdo and Boc are M-HhN-interacting proteins that are required for normal Hh signaling. They are type I integral membrane proteins with four extracellular immunoglobulin-like domains and two extracellular fibronectin type III domains. Biochemical and structural studies of complexes of Drosophila $\mathrm{HhN}$ and Ihog show that heparin induces dimerization of Ihog, a prerequisite for high-affinity interactions between $\mathrm{M}-\mathrm{HhN}$ and Ihog [30]. Biochemical and structural studies of complexes of mouse ShhN and Cdo revealed a different mode of binding, where a calcium-binding site in $\mathrm{ShhN}$ is important for the interaction [31]. Therefore, although the structures of fly $\mathrm{HhN}$ and mouse ShhN are conserved, the mode of interaction is not necessarily conserved in evolution.

\section{Localization and function}

An export signal peptide targets newly synthesized Hh to the endoplasmic reticulum, where autoprocessing, as well as palmitoylation, of the $\mathrm{HhN}$ domain occurs [26,28]. The modified $\mathrm{HhN}$ is released from the cell with the aid of the 12pass transmembrane protein Dispatched (Disp). Once released into the extracellular environment, $\mathrm{M}-\mathrm{HhN}$ interacts with a number of different proteins: the heparan-sulfate proteoglycan Dally-like (Dlp), and the proteins Ihog and growtharrest-specific 1 (Gas1) are positive regulators of Hh signaling, whereas Hh-interacting protein (Hip) acts as a negative regulator by sequestering $\mathrm{M}-\mathrm{HhN}$. The lipid modification of $\mathrm{HhN}$ as well as the extracellular protein interactions influence its extracellular movement and ensure correct shortand long-range signaling (see, for example, [28]).

The key function of $\mathrm{M}-\mathrm{HhN}$ as an extracellular signal is to inhibit the activity of the receptor Patched (Ptc), a 12-pass transmembrane protein. Ptc is closely related to Disp and shares similarity with the bacterial family of resistancenodulation division (RND) proton pumps that transport small molecules across membranes. Numerous reviews deal with the biological function of the Hh pathway and its components [32-52]. Figure 6 shows a summary of the pathway composed from Drosophila and mammalian data (although a number of important differences exist between the pathways in these two groups of organisms). Briefly, in the absence of $\mathrm{M}-\mathrm{HhN}$ binding, Ptc represses a signaling pathway that acts through Smoothened (Smo), a seven-pass G-protein-coupled receptor. Smo is negatively regulated by pro-vitamin D3, and is positively, but indirectly, regulated by oxysterols (oxygenated derivatives of cholesterol) [53-55]. 7-Dehydrocholesterol reductase, which converts pro-vitamin D3 into cholesterol, is also a regulator of $\mathrm{Hh}$ signaling [56]. Another important aspect of Smo activity is its subcellular localization. When MHhN binds to Ptc, the complex is internalized while Smo translocates to the cell membrane or - in mammals - to the primary cilia. Localization of Smo to the primary cilia is a fundamental requirement for the pathway to be active, and in the absence of M-HhN, Ptc inhibits this localization [57]. How exactly Ptc inhibits Smo is still not clear and numerous models are being contemplated (see, for example, [38,41,52]). Because of the similarity of Ptc to bacterial transporters, Ptc could secrete a pro-vitamin D3 or related molecule to inhibit Smo. Activated Smo is phosphorylated and signals via a cascade of microtubule-associated proteins to the nucleus, where the transcription factor Cubitus interruptus (Ci) in Drosophila or its mammalian counterparts, the Gli transcription factors, activate or repress target genes. Among the many target genes regulated by mammalian Gli1 are those for Ptc and Gli1 themselves. This results in feedback loops in which upregulation of Ptc leads to negative feedback, whereas upregulation of Gli1 leads to positive feedback.

In animal development, the secreted $\mathrm{M}-\mathrm{HhN}$ moiety functions as a morphogen. The Hh signaling pathway plays 


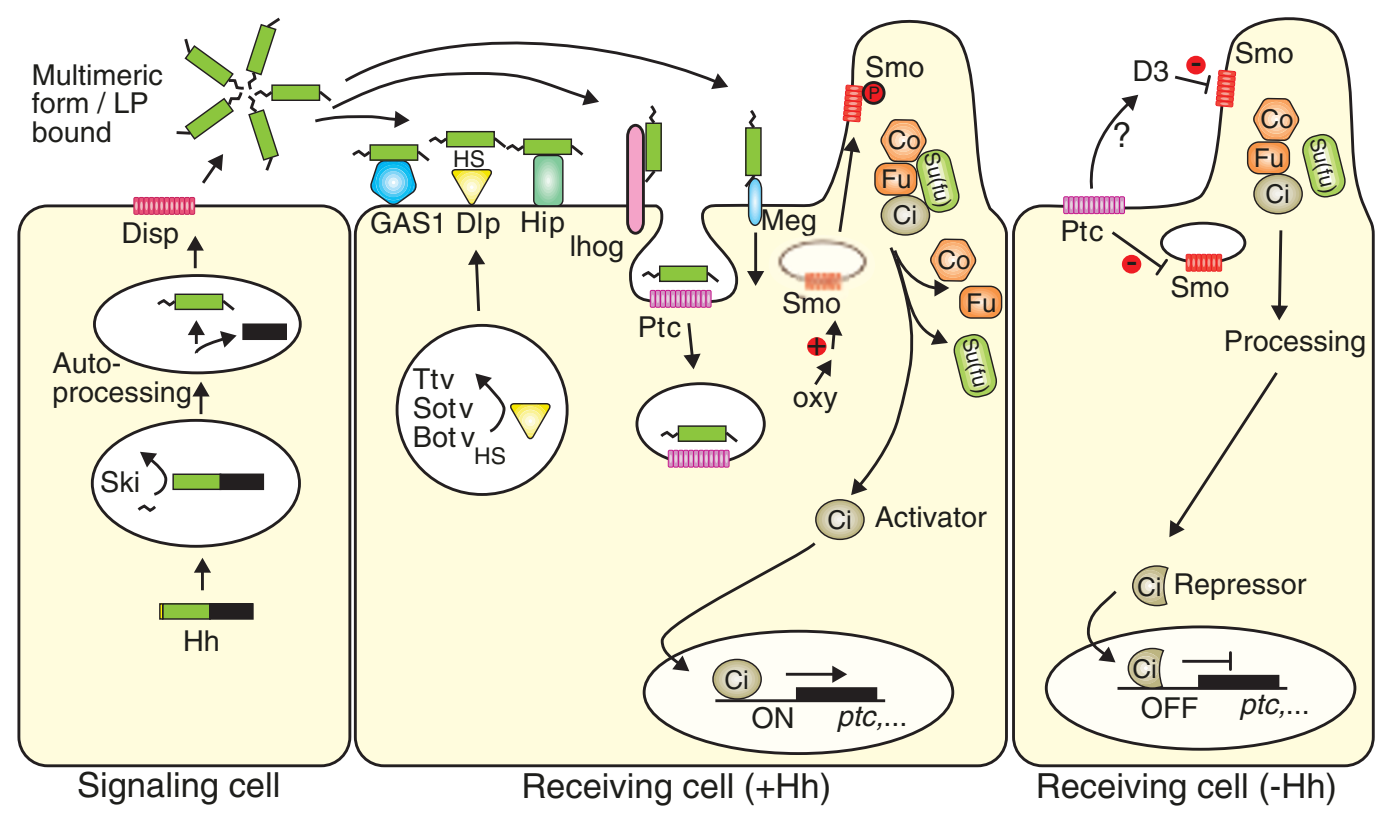

Figure 6

A simplified Hh signaling pathway, constructed from combined Drosophila and mammalian data. Hh is targeted to the endoplasmic reticulum by its signal peptide, is palmitoylated at its amino terminus by Rasp/Skinny Hedgehog (Ski), and autoprocessed. Lipidated HhN (M-HhN) is released by Dispatched (Disp) and forms multimers or associates with lipoproteins (LP) in the extracellular environment [32]. A number of molecules can interact with M-HhN and propagate or modulate its trafficking: the Dally-like protein (Dlp), which is modified by the heparan sulfate (HS) polymerases Tout-velu (Ttv), Sister of tout-velu (Sotv), and Brother of tout-velu (Botv), all members of the EXT family; the Hedgehog-interacting protein (Hip); and the Growth-arrestspecific I (Gas I) protein. Hip and GasI are not present in Drosophila. Megalin (Meg) is most probably involved in the recycling of M-HhN. Ihog is thought to function as co-receptor for $\mathrm{M}-\mathrm{HhN}$. M-HhN acts as an antagonistic ligand that represses the function of the receptor Patched (Ptc), a I2transmembrane protein related to Disp. Binding of $\mathrm{M}-\mathrm{HhN}$ to Ptc results in internalization. Smoothened (Smo) is a seven-pass membrane receptor, which is key for the transmission of the signal to the nucleus in the Hh pathway. Smo is inhibited by Ptc when not bound by M-HhN. When the inhibitory function of Ptc is released by M-HhN, Smo can translocate to the plasma membrane or - in mammals - to the primary cilium, and active Smo is phosphorylated (red P). Ptc may secrete pro-vitamin D3 or related compounds (D3) to inhibit Smo. Conversely, oxysterols (Oxy) can indirectly activate Smo [52,55]. The Hh pathway downstream of Smo displays some important differences between Drosophila and mammals. In Drosophila, when Smo is active, the signal passes through a complex comprising the kinesin-like molecule Costal 2 (Cos2), Fused (Fu), Suppressor of fused (Su(fu)) and Cubitus interruptus $(\mathrm{Ci})$, leading to the release of $\mathrm{Ci}$, which can then enter the nucleus to activate transcription. When $\mathrm{Smo}$ is inhibited, the Cos $2 / \mathrm{Fu} / \mathrm{Su}(\mathrm{fu}) / \mathrm{Ci}$ complex remains associated with microtubules, $\mathrm{Ci}$ is phosphorylated and is cleaved by Cos 2 . The $\mathrm{Ci}$ fragment now acts as a transcriptional repressor. In mammals, the targeting of Smo to primary cilia is essential for signal transduction. No obvious equivalents of Cos 2 and Fu exist in mammals. Instead, $\mathrm{Su}(\mathrm{fu})$ has a more prominent role in inhibiting the pathway. Gli I, Gli2, and Gli3 are the mammalian homologs of Ci; Glil and Gli2 activate transcription when Smo is active, whereas Gli3 is processed and becomes a repressor when Smo is inhibited. A number of components in the pathway, in particular downstream of Smo, are not shown in this figure.

many important roles in development, including conferring segment polarity on the body segments and patterning the wing in Drosophila, and patterning the neural tube in mammals $[39,48,58]$. Hh is also required for stem-cell maintenance, and mutations in the pathway lead to cancer. Increased activity of the pathway causes basal cell carcinoma and medulloblastoma [37,59-63]. For example, insufficient Ptc function leads to Gorlin syndrome in humans, one feature of which is an increased risk of basal cell skin cancer. In mammals, Shh, Dhh, and Ihh have partially redundant functions. Shh is the most widely expressed of the three paralogs, and regulates development from embryo to adult. Key roles are in patterning the neural tube: Shh is first expressed in the notochord, and later in the floor plate of the neural tube, where it produces a gradient of activity in the ventral neural tube. Shh is also expressed in the zone of polarizing activity of the limb buds and is important for limb and digit formation. Other roles of Shh include inner ear, eye, taste bud, and hair follicle development. Ihh is expressed in the primitive endoderm and is required for bone growth and pancreas development. Shh and Ihh both play roles in cardiovascular development. Dhh is expressed in the gonads, and Dhh-mutant males are sterile [39,48,64].

\section{Frontiers}

Despite substantial insights into the Hh signaling pathway, there are still many gaps in our understanding. How, and in 
which forms, the M-HhN morphogen travels from the signaling cells to the target cells requires further investigation. Obviously, the number of potential interactors in the extracellular matrix and extracellular space is vast, and any changes therein could influence how $\mathrm{M}-\mathrm{HhN}$ propagates. And could the M-HhN domain potentially have functions other than to regulate the Ptc-Smo interaction? Clearly, the amino-terminal domains of Hh-related proteins in protists and nematodes, as well as $\mathrm{Hh}$ in Enoplea [10] must have other functions, as there is no bona fide Hh signaling pathway in these organisms. The inhibition of Smo by Ptc and the role of sterol compounds also need further investigation to unravel the action of sterols on Smo, and to determine how Ptc is involved in this regulation. The $\mathrm{Hh}$ signaling pathway has been compared to the Wnt pathway, another key signaling pathway in development, since some of the molecules in the pathways have similarities to each other [65]. However, the Hh signaling pathway is unusual and different from other signaling pathways in that the primary morphogen, M-HhN, does not directly act on the key receptor, Smo. Perhaps the Smo signaling pathway was originally part of a sterol homeostasis pathway. M-HhN and Ptc could then be viewed as secondary modifiers of the Smo pathway. Did they originally have other functions? For example, the Ptc homolog PTC-1 in C. elegans functions in the absence of Smo and plays a role in oocyte cytokinesis [66].

A substantial number of components of the Smo signaling cascade leading to the nucleus have been uncovered, though many of the interactions still need to be better understood. Recently, however, a new Smo response pathway was uncovered that does not depend on transcription activation through Smo [67], opening the possibility that yet other aspects of the pathway downstream of Smo remain to be discovered. The importance of oxysterols in $\mathrm{Hh}$ signaling connects the Hh pathway with cholesterol homeostasis $[49,52,68,69]$. Hence, it will be a formidable challenge to unravel the interactions between sterol compounds, Hh, Ptc and Smo and to comprehend the kinetics and biophysical aspects of their subcellular localization. Understanding of all the regulatory controls and feedback loops in this signaling pathway will ultimately require computational modeling.

\section{Acknowledgements}

I would like to thank Peter Zaphiropoulos for critical reading of the manuscript. TRB is supported by the Center of Biosciences.

\section{References}

I. Nüsslein-Volhard C, Wieschaus E: Mutations affecting segment number and polarity in Drosophila. Nature 1980, 287:795-80I.

2. Mohler J, Vani K: Molecular organization and embryonic expression of the hedgehog gene involved in cell-cell communication in segmental patterning of Drosophila. Development 1992, I15:957-97I.

3. Lee JJ, von Kessler DP, Parks S, Beachy PA: Secretion and localized transcription suggest a role in positional signaling for products of the segmentation gene hedgehog. Cell 1992, 71:33-50.
4. Tabata T, Eaton S, Kornberg TB: The Drosophila hedgehog gene is expressed specifically in posterior compartment cells and is a target of engrailed regulation. Genes Dev 1992, 6:2635-2645.

5. Echelard Y, Epstein DJ, St-Jacques B, Shen L, Mohler J, McMahon JA, McMahon AP: Sonic hedgehog, a member of a family of putative signaling molecules, is implicated in the regulation of CNS polarity. Cell 1993, 75:1417-1430.

6. Krauss S, Concordet J-P, Ingham PW: A functionally conserved homolog of the Drosophila segment polarity gene $h h$ is epxressed in tissues with polarizing activity in zebrafish embryos. Cell 1993. 75: | $43|-| 444$

7. Riddle R, Johnson RL, Laufer E, Tabin C: Sonic hedgehog mediates the ZPA of polarizing activity. Cell I993, 75:|40I-|4I6.

8. Matus DQ, Magie CR, Pang K, Martindale MQ, Thomsen GH: The Hedgehog gene family of the cnidarian, Nematostella vectensis, and implications for understanding metazoan Hedgehog pathway evolution. Dev Biol 2008, 313:50I-5I8.

9. Aspöck G, Kagoshima H, Niklaus G, Bürglin TR: Caenorhabditis elegans has scores of hedgehog-related genes: sequence and expression analysis. Genome Res 1999, 9:909-923.

10. Bürglin TR: Evolution of hedgehog and hedgehog-related genes, their origin from Hog proteins in ancestral eukaryotes and discovery of a novel Hint motif. BMC Genomics 2008, 9:127.

II. Koonin EV: A protein splice-junction motif in hedgehog family proteins. Trends Biochem Sci 1995, 20:141-142.

12. Saleh L, Perler FB: Protein splicing in cis and in trans. Chem Rec 2006, 6I:83-193.

13. Dassa B, Pietrokovski S: Origin and evolution of inteins and other Hint domains. In: Homing Endonucleases and Inteins. Edited by Belfort M, Stoddard BL, Wood DW, Derbyshire V. Berlin: Springer 2005.

14. Hall TMT, Porter JA, Young KE, Koonin EV, Beachy PA, Leahy DJ: Crystal structure of a Hedgehog autoprocessing domain: homology between Hedgehog and self-splicing proteins. Cell I997, 91:85-97.

15. Amitai G, Belenkiy O, Dassa B, Shainskaya A, Pietrokovski S: Distribution and function of new bacterial intein-like protein domains. Mol Microbiol 2003, 47:6I-73.

16. Dassa B, Yanai I, Pietrokovski S: New type of polyubiquitin-like genes with intein-like autoprocessing domains. Trends Genet 2004, 20:538542.

17. Requena N, Mann P, Hampp R, Franken P: Early developmentally regulated genes in the arbuscular mycorrhizal fungus Glomus mosseae: identification of $G m G I N I$, a novel gene with homology to the C-terminus of metazoan hedgehog proteins. Plant Soil 2002, 244: I 29-I 39.

18. Snell EA, Brooke NM, Taylor WR, Casane D, Philippe H, Holland PW: An unusual choanoflagellate protein released by Hedgehog autocatalytic processing. Proc Biol Sci 2006, 273:40I-407.

19. Adamska M, Matus DQ, Adamski M, Green K, Rokhsar DS, Martindale MQ, Degnan BM: The evolutionary origin of hedgehog proteins. Curr Biol 2007, I7:R836-R837.

20. Nichols SA, Dirks W, Pearse JS, King N: Early evolution of animal cell signaling and adhesion genes. Proc Natl Acad Sci USA 2006 103:12451-12456.

21. Beachy PA, Cooper MK, Young KE, von Kessler DP, Park W-J, Hall TMT, Leahy DJ, Porter JA: Multiple roles of cholesterol in hedgehog protein biogenesis and signaling. Cold Spring Harb Symp Quant Bio 1997, 62:19|-204.

22. Porter JA, Ekker SC, Park WJ, von Kessler DP, Young KE, Chen $\mathrm{CH}$, Ma Y, Woods AS, Cotter RJ, Koonin EV, Beachy PA: Hedgehog patterning activity: role of a lipophilic modification mediated by the carboxy-terminal autoprocessing domain. Cell 1996, 86:2I-34.

23. Hall TMT, Porter JA, Beachy PA, Leahy DJ: A potential catalytic site revealed by the I.7- $\AA$ crystal structure of the amino-terminal signalling domain of Sonic hedgehog. Nature 1995, 378:2 I2-216.

24. Fuse N, Maiti T, Wang B, Porter JA, Hall TM, Leahy DJ, Beachy PA: Sonic hedgehog protein signals not as a hydrolytic enzyme but as an apparent ligand for patched. Proc Natl Acad Sci USA 1999, 96: 10992-10999.

25. Chamoun Z, Mann RK, Nellen D, von Kessler DP, Bellotto M, Beachy PA, Basler K: Skinny hedgehog, an acyltransferase required for palmitoylation and activity of the hedgehog signal. Science 200I, 293:2080-2084.

26. Buglino JA, Resh MD: Hhat is a palmitoylacyltransferase with specificity for N-palmitoylation of Sonic Hedgehog. J Biol Chem 2008, 283:22076-22088.

27. Chen MH, Li YJ, Kawakami T, Xu SM, Chuang PT: Palmitoylation is required for the production of a soluble multimeric Hedgehog protein complex and long-range signaling in vertebrates. Genes Dev 2004, 18:64I-659. 
28. Gallet A, Ruel L, Staccini-Lavenant L, Therond PP: Cholesterol modification is necessary for controlled planar long-range activity of Hedgehog in Drosophila epithelia. Development 2006, I33:407-4I 8.

29. Panakova D, Sprong H, Marois E, Thiele C, Eaton S: Lipoprotein particles are required for Hedgehog and Wingless signalling. Nature 2005, 435:58-65.

30. McLellan JS, Yao S, Zheng X, Geisbrecht BV, Ghirlando R, Beachy PA, Leahy DJ: Structure of a heparin-dependent complex of Hedgehog and lhog. Proc Natl Acad Sci USA 2006, 103: I7208-I72I3.

31. McLellan JS, Zheng X, Hauk G, Ghirlando R, Beachy PA, Leahy DJ: The mode of Hedgehog binding to lhog homologues is not conserved across different phyla. Nature 2008 doi: $10.1038 /$ nature07358.

32. Cohen MM Jr: The hedgehog signaling network. Am J Med Genet A 2003, 123:5-28.

33. Bijlsma MF, Spek CA, Peppelenbosch MP: Hedgehog: an unusual signal transducer. BioEssays 2004, 26:387-394.

34. Huangfu D, Anderson KV: Signaling from Smo to Ci/Gli: conservation and divergence of Hedgehog pathways from Drosophila to vertebrates. Development 2006, 133:3-I4.

35. Østerlund T, Kogerman P: Hedgehog signalling: how to get from Smo to $\mathrm{Ci}$ and Gli. Trends Cell Biol 2006, I6:I76-I80.

36. Wilson CW, Chuang PT: New "Hogs" in Hedgehog transport and signal reception. Cell 2006, 125:435-438.

37. Jacob L, Lum L: Deconstructing the hedgehog pathway in development and disease. Science 2007, 318:66-68.

38. Wang Y, McMahon AP, Allen BL: Shifting paradigms in Hedgehog signaling. Curr Opin Cell Biol 2007, 19:159-165.

39. Dessaud E, McMahon AP, Briscoe J: Pattern formation in the vertebrate neural tube: a sonic hedgehog morphogen-regulated transcriptional network. Development 2008, I35:2489-2503.

40. Ruiz-Gómez A, Molnar C, Holguín H, Mayor F Jr, de Celis JF: The cell biology of Smo signalling and its relationships with GPCRs. Biochim Biophys Acta 2007, I768:901-912.

41. Rohatgi R, Scott MP: Patching the gaps in Hedgehog signalling. Nat Cell Biol 2007, 9:1005-1009.

42. Kang JS, Zhang W, Krauss RS: Hedgehog signaling: cooking with Gas I. Sci STKE 2007, 2007:pe50.

43. Ingham P: Micromanaging the response to Hedgehog. Nat Genet 2007, 39: $145-146$

44. Katoh Y, Katoh M: Hedgehog signaling, epithelial-to-mesenchymal transition and miRNA. Int J Mol Med 2008, 22:27I-275.

45. Fernández-Zapico ME: Primers on molecular pathways - GLI: more than just Hedgehog? Pancreatology 2008, 8:227-229.

46. Ocbina PJ, Anderson KV: Intraflagellar transport, cilia, and mammalian Hedgehog signaling: analysis in mouse embryonic fibroblasts. Dev Dyn 2008, 237:2030-2038.

47. Hooper JE, Scott MP: Communicating with Hedgehogs. Nat Rev Mol Cell Biol 2005, 6:306-3I7.

48. Varjosalo M, Taipale J: Hedgehog: functions and mechanisms. Genes Dev 2008, 22:2454-2472.

49. Breitling R: Greased hedgehogs: new links between hedgehog signaling and cholesterol metabolism. BioEssays 2007, 29:1 085-1094.

50. Ingham PW: Hedgehog signalling. Curr Biol 2008, I8:R238-R24I.

5I. Kalderon D: Hedgehog signaling: a smoothened conformational switch. Curr Biol 2008, I8:R64-R66.

52. Eaton S: Multiple roles for lipids in the Hedgehog signalling pathway. Nat Rev Mol Cell Biol 2008, 9:437-445.

53. Bijlsma MF, Spek CA, Zivkovic D, van de Water S, Rezaee F, Peppelenbosch MP: Repression of smoothened by patched-dependent (pro-)vitamin D3 secretion. PLoS Biol 2006, 4:e232.

54. Corcoran RB, Scott MP: Oxysterols stimulate Sonic hedgehog signal transduction and proliferation of medulloblastoma cells. Proc Nat Acad Sci USA 2006, 103:8408-84I 3.

55. Dwyer JR, Sever N, Carlson M, Nelson SF, Beachy PA, Parhami F: Oxysterols are novel activators of the hedgehog signaling pathway in pluripotent mesenchymal cells. J Biol Chem 2007, 282:8959-8968.

56. Koide T, Hayata T, Cho KW: Negative regulation of Hedgehog signaling by the cholesterogenic enzyme 7-dehydrocholesterol reductase. Development 2006, I33:2395-2405.

57. Rohatgi R, Milenkovic L, Scott MP: Patched I regulates hedgehog signaling at the primary cilium. Science 2007, 317:372-376.

58. Sanson B: Generating patterns from fields of cells. Examples from Drosophila segmentation. EMBO Rep 200I, 2:1083-1088.

59. Beachy PA, Karhadkar SS, Berman DM: Tissue repair and stem cell renewal in carcinogenesis. Nature 2004, 432:324-33I.
60. Rubin LL, de Sauvage FJ: Targeting the Hedgehog pathway in cancer. Nat Rev Drug Discov 2006, 5: I026-I033.

61. Clement V, Sanchez P, de Tribolet N, Radovanovic I, Ruiz i Altaba A HEDGEHOG-GLII signaling regulates human glioma growth, cancer stem cell self-renewal, and tumorigenicity. Curr Biol 2007, I7:I65172.

62. Xie J: Implications of hedgehog signaling antagonists for cancer therapy. Acta Biochim Biophys Sin 2008, 40:670-680.

63. Tang JY, So PL, Epstein EH Jr: Novel Hedgehog pathway targets against basal cell carcinoma. Toxicol Appl Pharmacol 2007, 224:257264.

64. Bijlsma MF, Peppelenbosch MP, Spek CA: Hedgehog morphogen in cardiovascular disease. Circulation 2006, I|4:1985-1991.

65. Nusse R: Wnts and Hedgehogs: lipid-modified proteins and similarities in signaling mechanisms at the cell surface. Development 2003, 130:5297-5305.

66. Kuwabara $\mathrm{P}$, Lee $\mathrm{M}-\mathrm{H}$, SchedI T, Jefferis GSXE: A C. elegans patched gene, ptc-l, functions in germ-line cytokinesis. Genes Dev 2000, 14:1933-1944.

67. Bijlsma MF, Borensztajn KS, Roelink H, Peppelenbosch MP, Spek CA Sonic hedgehog induces transcription-independent cytoskeletal rearrangement and migration regulated by arachidonate metabolites. Cell Signal 2007, 19:2596-2604.

68. Gill S, Chow R, Brown AJ: Sterol regulators of cholesterol homeostasis and beyond: the oxysterol hypothesis revisited and revised. Prog Lipid Res 2008, doi:10.1016/j.plipres.2008.04.002.

69. Javitt NB: Oxysterols: novel biologic roles for the 21 st century. Steroids 2008, 73:149-157.

70. Mann RK, Beachy PA: Novel lipid modifications of secreted protein signals. Annu Rev Biochem 2004, 73:891-923.

7I. Baldauf SL: The deep roots of eukaryotes. Science 2003, 300:I7031706

72. DOE Joint Genome Institute [http://www.jgi.doe.gov]

73. Hirshfield HI: The protozoan fauna of some species of intertidal invertebrates in Southern California. J Parasitol 1950, 36:107-II2. 